\title{
Continuous glucose monitoring targets in type 1 diabetes pregnancy: every $5 \%$ time in range matters
}

\author{
Helen R. Murphy ${ }^{1}$ \\ Received: 4 April 2019 / Accepted: 17 April 2019 / Published online: 3 June 2019 \\ (C) The Author(s) 2019
}

\begin{abstract}
With randomised trial data confirming that continuous glucose monitoring (CGM) is associated with improvements in maternal glucose control and neonatal health outcomes, CGM is increasingly used in antenatal care. Across pregnancy, the ambition is to increase the CGM time in range (TIR), while reducing time above range (TAR), time below range (TBR) and glycaemic variability measures. Pregnant women with type 1 diabetes currently spend, on average, $50 \%$ (12 h), 55\% $(13 \mathrm{~h})$ and $60 \%(14 \mathrm{~h})$ in the target range of $3.5-7.8 \mathrm{mmol} / 1(63-140 \mathrm{mg} / \mathrm{dl})$ during the first, second and third trimesters, respectively. Hyperglycaemia, as measured by TAR, reduces from $40 \%(10 \mathrm{~h})$ to $33 \%(8 \mathrm{~h})$ during the first to third trimester. A TIR of $>70 \%(16 \mathrm{~h}, 48 \mathrm{~min})$ and a TAR of $<25 \%(6 \mathrm{~h})$ is achieved only in the final weeks of pregnancy. CGM TBR data are particularly sensor dependent, but regardless of the threshold used for individual patients, spending $\geq 4 \%$ of time $(1 \mathrm{~h})$ below $3.5 \mathrm{mmol} / 1$ or $\geq 1 \%$ of time $(15 \mathrm{~min})$ below $3.0 \mathrm{mmol} / \mathrm{l}$ is not recommended. While maternal hyperglycaemia is a well-established risk factor for obstetric and neonatal complications, CGM-based risk factors are emerging. A 5\% lower TIR and 5\% higher TAR during the second and third trimesters is associated with increased risk of large for gestational age infants, neonatal hypoglycaemia and neonatal intensive care unit admissions. For optimal neonatal outcomes, women and clinicians should aim for a TIR of $>70 \%$ (16 h, $48 \mathrm{~min})$ and a TAR of $<25 \%$ (6 h), from as early as possible during pregnancy.
\end{abstract}

Keywords Continuous glucose monitoring $\cdot$ Hyperglycaemia $\cdot$ Pregnancy $\cdot$ Type 1 diabetes

\begin{tabular}{|c|c|}
\hline \multicolumn{2}{|c|}{ Abbreviations } \\
\hline ATTD & $\begin{array}{l}\text { Advanced Technologies \& Treatments for } \\
\text { Diabetes }\end{array}$ \\
\hline $\mathrm{CE}$ & Conformité Européenne \\
\hline CGM & Continuous glucose monitoring \\
\hline iCGM & Intermittently viewed CGM \\
\hline LGA & Large for gestational age \\
\hline NICU & Neonatal intensive care unit \\
\hline rt-CGM & Real-time CGM \\
\hline TAR & Time above range \\
\hline TBR & Time below range \\
\hline TIR & Time in range \\
\hline
\end{tabular}

Helen R. Murphy

helen.murphy@uea.ac.uk; hm386@medschl.cam.ac.uk

1 Norwich Medical School, University of East Anglia, Floor 2, Bob Champion Research and Education Building, Norwich NR4 7UQ, UK
In their observational cohort study of 186 pregnancies complicated by type 1 diabetes, Kristensen et al document fetal exposure to maternal glycaemia using detailed continuous glucose monitoring (CGM) measures [1]. Combining data from 92 real-time CGM (rt-CGM) and 94 intermittently viewed CGM (iCGM) 'real-world' users, they measured percentage of time spent in, above and below the target glucose range of $3.5-7.8 \mathrm{mmol} / \mathrm{l}(63-140 \mathrm{mg} / \mathrm{dl})$, as well as mean glucose and glycaemic variability metrics throughout pregnancy. As expected, maternal glycaemia improved across gestation, with a decrease in mean glucose, $\mathrm{HbA}_{1 \mathrm{c}}$ and glycaemic variability. The authors confirm that the established clinical measures, $\mathrm{HbA}_{1 \mathrm{c}}$ and mean glucose, are good markers of the suboptimal glucose control associated with large for gestational age infants and neonatal complications. In addition, they describe the gestational changes in CGM measures. These data provide important new insights into the CGM measures associated with suboptimal maternal glucose control and risk of neonatal complications. They confirm the need for dynamic glycaemic metrics beyond $\mathrm{HbA}_{1 \mathrm{c}}$ and will inform the 
development of evidence-based CGM targets in type 1 diabetes pregnancy.

\section{CGM measures across gestation}

Across pregnancy, the ambition is to increase the time in range (TIR) while reducing time above range (TAR), time below range (TBR) and glycaemic variability. With 84 women using CGM from before pregnancy, Kristensen et al demonstrate a substantial 15 percentage point increase in time in range (TIR $3.5-7.8 \mathrm{mmol} / \mathrm{l}$ ) during the first trimester, rising from $40 \%$ TIR (10 h/day) in the early post-conception period to $55 \%$ TIR ( $13.2 \mathrm{~h} /$ day) by the end of the first trimester. There follows a striking lack of improvement across the second trimester, with a 5 percentage point increase bringing the third trimester TIR to $60 \%$ ( $14.4 \mathrm{~h} /$ day). This is mirrored by a reduction in first trimester time above target range (TAR $>7.8 \mathrm{mmol} / \mathrm{l}$ ), and minimal further reductions in the second and third trimesters.

Despite differences in patient populations, study design, statistical analyses, CGM systems and duration of sensor use, these Swedish CGM profiles are remarkably similar to those in the multicentre CONCEPTT trial [2]. The CONCEPTT control group (self-monitoring of blood glucose) had masked CGM profiles recorded at approximately 12, 24 and 34 weeks' gestation, which are indistinguishable from the first, second and third trimester profiles described by Kristensen et al. Both report approximately 50\% TIR 3.5$7.8 \mathrm{mmol} / \mathrm{l}$ and $40 \% \mathrm{TAR}>7.8 \mathrm{mmol} / \mathrm{l}$ in the first trimester, improving to an average of $60 \%$ TIR $3.5-7.8 \mathrm{mmol} / 1$ and $33 \%$ TAR > $7.8 \mathrm{mmol} / \mathrm{l}$ in the third trimester (Table 1). These data confirm the gap between our expectations of tight glucose control and the reality of achieving the CGM targets in standard antenatal care. The 2019 Advanced Technologies \& Treatments for Diabetes (ATTD) consensus recommends targets for TIR of $>70 \%$ (16 h, $48 \mathrm{~min}$ ) and TAR of $<25 \%(6 \mathrm{~h})$, from as early as possible during pregnancy [3]. In the Swedish and CONCEPTT studies, women only achieved these targets towards the end of the third trimester, too late for optimal neonatal outcomes $[1,2]$.

\section{CGM measures in relation to $\mathrm{HbA}_{1 \mathrm{c}}$}

The limitations of $\mathrm{HbA}_{1 \mathrm{c}}$ when evaluating individual glucose control are well recognised [4]. Among women without diabetes, $\mathrm{HbA}_{1 \mathrm{c}}$ is lower during pregnancy, as a result of lower mean glucose [5] and artefactual lowering that is unrelated to maternal glycaemia [6]. During early pregnancy, artefactual lowering is attributed to increased erythropoiesis and shortened red cell life span $[5,6]$. We previously described gestational reductions of up to $11 \mathrm{~mol} / \mathrm{mol}(1 \%) \mathrm{HbA}_{1 \mathrm{c}}$, without improvement in self-monitored glucose levels [7]. Women with higher $\mathrm{HbA}_{1 \mathrm{c}}$ values have the largest $\mathrm{HbA}_{1 \mathrm{c}}$ reductions, which can be falsely reassuring in those with very poor control [7].

Astute readers of the paper by Kristensen et al will notice that maternal $\mathrm{HbA}_{1 \mathrm{c}}$ levels remained unchanged from the second to the third trimester despite a $0.3 \mathrm{mmol} / 1$ reduction in mean glucose and a $5 \%$ percentage point increase in TIR (from $55 \%$ to $60 \%$ ). Similar discrepancies between third trimester $\mathrm{HbA}_{1 \mathrm{c}}$ and improving CGM glycaemic measures (TIR, TAR) were observed in CONCEPTT. Twice as many CONCEPTT participants achieved target $\mathrm{HbA}_{1 \mathrm{c}}$ compared with target TIR, suggesting that a TIR of $>70 \%$ is a more ambitious goal.

A formula for converting CGM-derived glucose mean glucose into an estimated $\mathrm{HbA}_{1 \mathrm{c}}$ during pregnancy has been proposed [8]. To avoid confusion with laboratory $\mathrm{HbA}_{1 \mathrm{c}}$ assays, the CGM estimated $\mathrm{HbA}_{1 \mathrm{c}}$ is now more appropriately referred to as a glucose management indicator [9]. Law et al analysed data from two early randomised trials of intermittent retrospective or rt-CGM $[10,11]$, and these results suggested that, to minimise fetal overgrowth, clinicians should focus on mean CGM glucose levels, with a recommended target of 6.4$6.7 \mathrm{mmol} / 1$ (115-120 mg/dl) [12]. Notably, this target was not achieved, either in the early $[10,11]$ or in the recent CGM studies $[1,2]$ until the final weeks of pregnancy.

\section{CGM measures in relation to fetal and neonatal outcomes}

During organogenesis, the developing fetus is particularly susceptible to maternal glucose excursions, and peri-conception hyperglycaemia as measured by $\mathrm{HbA}_{1 \mathrm{c}}$ is strongly associated with increased risk for major congenital anomaly, stillbirth and neonatal death [13-16]. Large population-based CGM studies are required to confirm the associations between CGM measures and serious adverse pregnancy outcomes. However, for commonly occurring obstetric and neonatal complications, including large for gestational age (LGA) infants, neonatal intensive care unit (NICU) admissions and neonatal hypoglycaemia [13-16], CGM-based risk markers are emerging.

Kristensen et al found that a 5-7\% lower TIR during the second and third trimesters was associated with increased risk of LGA and neonatal outcomes, including macrosomia, shoulder dystocia, neonatal hypoglycaemia or NICU admissions of $>24$ h duration. Mothers of infants with vs without LGA had lower TIR during the second (52\% vs 58\%) and third trimesters $(58 \%$ vs $62 \%)$. Likewise, mothers of infants with complications of macrosomia, shoulder dystocia, neonatal hypoglycaemia or NICU admissions had a 5-6\% lower TIR 
Table 1 Patterns of glycaemia among pregnant CGM users with type 1 diabetes

\begin{tabular}{|c|c|c|c|}
\hline Glucose measures & $\begin{array}{l}\text { Kristensen et al, } 2019[1] \\
\text { iCGM or rt-CGM } \\
N=186^{\mathrm{a}}\end{array}$ & $\begin{array}{l}\text { Feig et al } 2017 \text { [2] } \\
\text { rt-CGM } \\
N=108^{\mathrm{a}}\end{array}$ & CGM target \\
\hline \multicolumn{4}{|c|}{ Laboratory $\mathrm{HbA}_{1 \mathrm{c}}, \mathrm{mmol} / \mathrm{mol}(\%)$} \\
\hline Trimester 1 & $52 \pm 10.5(6.9 \pm 1.0)$ & $51 \pm 7 \cdot 3(6 \cdot 8 \pm 0 \cdot 7)$ & \\
\hline Trimester 2 & $45 \pm 7.9(6.3 \pm 0.7)$ & $44 \pm 6.5(6.2 \pm 0.5)$ & \\
\hline Trimester 3 & $46 \pm 7.6(6.3 \pm 0.7)$ & $46 \pm 6.7(6 \cdot 3 \pm 0 \cdot 6)$ & \\
\hline \multicolumn{4}{|c|}{ CGM mean glucose, mmol/1 } \\
\hline Trimester 1 & $7.8 \pm 1.4$ & $7 \cdot 3 \pm 1 \cdot 2$ & \\
\hline Trimester 2 & $7.4 \pm 1.2$ & $7.6 \pm 1.2$ & \\
\hline Trimester 3 & $7.1 \pm 1.1$ & $6 \cdot 7 \pm 0 \cdot 9$ & \\
\hline \multicolumn{4}{|c|}{ TIR 3.5-7.8 mmol/ $/ \mathrm{l}^{\mathrm{b}}(\%)$} \\
\hline Trimester 1 & $50 \pm 14$ & $52 \pm 13$ & $>70 \%$ \\
\hline Trimester 2 & $55 \pm 14$ & $53 \pm 15$ & $>70 \%$ \\
\hline Trimester 3 & $60 \pm 13$ & $68 \pm 13$ & $>70 \%$ \\
\hline \multicolumn{4}{|c|}{$\mathrm{TAR}>7.8 \mathrm{mmol} / \mathrm{l}^{\mathrm{c}}(\%)$} \\
\hline Trimester 1 & $43 \pm 15$ & $39(28-49)$ & $<25 \%$ \\
\hline Trimester 2 & $38 \pm 15$ & $43(29-54)$ & $<25 \%$ \\
\hline Trimester 3 & $34 \pm 15$ & $27(19-37)$ & $<25 \%$ \\
\hline \multicolumn{4}{|c|}{$\mathrm{TBR}<3.5 \mathrm{mmol} / \mathrm{l}^{\mathrm{d}}(\%)$} \\
\hline Trimester 1 & $7 \pm 5$ & $8(4-14)$ & $<4 \%$ \\
\hline Trimester 2 & $7 \pm 5$ & $3(1-6)$ & $<4 \%$ \\
\hline Trimester 3 & $6 \pm 5$ & $3(1-6)$ & $<4 \%$ \\
\hline \multicolumn{4}{|c|}{ Glycaemic variability $(\% \mathrm{CV})^{\mathrm{e}}$} \\
\hline Trimester 1 & $40 \pm 7$ & $42(38-47)$ & $\leq 36 \%$ \\
\hline Trimester 2 & $38 \pm 6$ & $35(31-39)$ & $\leq 36 \%$ \\
\hline Trimester 3 & $36 \pm 6$ & $32(28-37)$ & $\leq 36 \%$ \\
\hline
\end{tabular}

${ }^{a}$ Continuous glucose measures reported were obtained using rt-CGM and iCGM throughout pregnancy by Kristensen et al and at 10, 24 and 34 weeks in the group using rt-CGM by Feig et al

${ }^{\mathrm{b}}$ TIR refers to $\%$ of time spent in range 3.5-7.8 $\mathrm{mmol} / \mathrm{l}(63-140 \mathrm{mg} / \mathrm{dl})$. The TIR target 3.5-7.8 mmol/1 (63$140 \mathrm{mg} / \mathrm{dl}$ ) proposed by the ATTD consensus group is $>70 \%$ (16 h $48 \mathrm{~min}$ ) in type 1 diabetes pregnancy

${ }^{\mathrm{c}}$ TAR refers to $\%$ of time spent $>7.8 \mathrm{mmol} / \mathrm{l}(>140 \mathrm{mg} / \mathrm{dl})$. The TAR target $>7.8 \mathrm{mmol} / 1$ ( $\left.>140 \mathrm{mg} / \mathrm{dl}\right)$ proposed by the ATTD consensus group is $<25 \%(6 \mathrm{~h})$ in type 1 diabetes pregnancy. Values are means $\pm \mathrm{SD}$ or median (interquartile range) as reported in the publications by Kristensen et al [1] and Feig et al [2]

${ }^{\mathrm{d}}$ TBR refers to the $\%$ of time spent $<3.5 \mathrm{mmol} / 1(<70 \mathrm{mg} / \mathrm{dl})$. The TBR target $<3.5 \mathrm{mmol} / \mathrm{l}(<70 \mathrm{mg} / \mathrm{dl})$ proposed by the ATTD consensus group is $<4 \%$ ( $1 \mathrm{~h}$ ) in type 1 diabetes pregnancy. rt-CGM users spent less time below $3.5 \mathrm{mmol} / \mathrm{l}$ compared with iCGM users in the study by Kristensen et al [1]

${ }^{\mathrm{e}}$ Glucose coefficient of variation (CV) thresholds for stable $\leq 36 \%$ and unstable $>36 \%$ are based on thresholds outside of pregnancy
(TIR 52\% vs $57 \%$ and TIR 56\% vs $62 \%$ ) during the second and third trimesters.

In CONCEPTT, we also found that rt-CGM users (compared with self-monitoring) achieved a 5-7\% higher TIR in the second and third trimesters, and this was associated with a halving in the odds ratio for LGA, neonatal hypoglycaemia and NICU admissions of $>24 \mathrm{~h}$ duration [2]. Taken together, these data indicate that relatively small (5\%) increments in TIR are associated with clinically relevant improvements in neonatal health outcomes. Importantly, TIR increments are attainable and not influenced by gestational changes in erythropoiesis, red cell life span or iron deficiency.

\section{CGM measures in relation to maternal hypoglycaemia}

Outside of pregnancy, percentage of TBR $<3.9 \mathrm{mmol} / \mathrm{l}$ and TBR $<3.0 \mathrm{mmol} / 1$ have both been associated with clinical episodes of severe hypoglycaemia [17]. During normal healthy pregnancy, glucose levels are approximately $20 \%$ 
lower [18]. A TBR threshold of less than $3.5 \mathrm{mmol} / \mathrm{l}$, was used in the Swedish and CONCEPTT studies [1, 2]. Kristensen et al demonstrate a substantial (almost twofold) increase in the percentage of time spent below $3.5 \mathrm{mmol} / \mathrm{l}$, starting from 6 weeks and peaking at 12-16 weeks' gestation. This is consistent with the well-recognised time-frame associated with maternal risk of severe hypoglycaemia [19]. As maternal hypoglycaemia is the rate-limiting factor for achieving tight glycaemic targets in early pregnancy, these data suggest that the target of minimising time spent below $3.5 \mathrm{mmol} / \mathrm{l}$ to less than $4 \%$ ( $1 \mathrm{~h}$ per day) is most challenging until around 16 weeks' gestation.

Kristensen et al did not report severe hypoglycaemia events. In CONCEPTT there were too few severe hypoglycaemia episodes, (14 with pump, 13 with multiple daily injection) to examine associations with CGM time below range thresholds. The time spent below $3.5 \mathrm{mmol} / \mathrm{l}$ halved both in insulin pump and multiple daily injection users (from $6 \%$ to $3 \%$ and from $8 \%$ to $4 \%$ ) from 12 to 34 weeks' gestation [20]. Taken together, the Swedish and CONCEPTT data suggest that, with contemporary antenatal care, the proposed Advanced Technologies \& Treatments for Diabetes (ATTD) consensus recommendation of not more than $4 \%$ of time $(1 \mathrm{~h} /$ day) spent below $3.5 \mathrm{mmol} / \mathrm{l}$ is safely achievable, especially after 16 weeks. As CGM time below range data are highly skewed, increasing the lower threshold to $3.9 \mathrm{mmol} / \mathrm{l}$, is associated with a substantial two- to threefold increase in time spent below range. We previously reported up to $15 \%$ of time ( $3 \mathrm{~h} 45 \mathrm{~min}$ ) below $3.9 \mathrm{mmol} / \mathrm{l}$ across type 1 diabetes pregnancy. Kristensen et al report approximately $10 \%$ of time ( $2.4 \mathrm{~h} /$ day) spent below $3.5 \mathrm{mmol} / \mathrm{l}$ in iCGM users. CGM data on time below range are particularly sensor dependent, but regardless of the threshold used for individual patients in clinical practice, spending $\geq 4 \%$ of time ( $1 \mathrm{~h} /$ day) below $3.5 \mathrm{mmol} /$ 1 or $\geq 1 \%$ of time ( $15 \mathrm{~min} /$ day) below $3.0 \mathrm{mmol} / 1$ is not recommended.

Once maternal insulin sensitivity starts to decline, typically around 18-20 weeks' gestation, the challenge is to minimise postprandial hyperglycaemia [21]. While modern insulin analogues [22, 23], rt-CGM [24] and hybrid closed-loop systems [25] all contribute to reducing hypoglycaemia in pregnancy, optimising hyperglycaemia requires early prandial bolus insulin (30-45 min before meals in late gestation) [26] and meticulous attention to dietary intake for meals and snacks [27].

\section{iCGM or rt-CGM?}

The factory-calibrated Freestyle Libre iCGM used in the study by Kerstensen et al [1] is more affordable and free from the alarms that frustrate rt-CGM users [28]. A study among 74 pregnant women (39 GDM, 24 type 1, 11 type 2 diabetes) led to a Conformité Européenne (CE) mark meaning that it complies with health, safety and environmental protection standards. It is the first sensor with a CE mark specifically for use during pregnancy. The accuracy of the Freestyle Libre sensor is acceptable and comparable between pregnant and non-pregnant users [29]. We found similar agreement between rt-CGM sensor accuracy in early and late gestation and between pregnant and non-pregnant users [30]. Thus, it is generally accepted that the sensor accuracy of iCGM and/or rt-CGM is not affected by gestational physiology.

In the study by Kristensen et al, women with iCGM appeared to spend more time below range at all gestational ages. Whether this relates to the diabetes self-management behaviours of rt-CGM users to prevent and/or avoid hypoglycaemia or to sensor accuracy of iCGM at lower glucose concentrations is unknown. All CGM sensors are less reliable at glucose levels below $3.5 \mathrm{mmol} / \mathrm{l}$. However, iCGM users spent strikingly large proportion of time (10\%) below target during the latter part of the first and third trimesters (Fig. 1c in [1]). The apparently high rates of time below target reported during the third trimester are unexpected and if women are then snacking to avoid perceived hypoglycaemia this could potentially undermine efforts to optimise glucose control in late pregnancy.

Despite baseline differences in maternal characteristics (longer duration of type 1 diabetes, a higher proportion of insulin pump users among the women using rt-CGM), Kristensen et al found that rates of LGA and neonatal composite outcome were comparable between iCGM and rt-CGM users. An adequately powered, large scale, randomised controlled trial would be required to demonstrate that iCGM is non-inferior to rt-CGM. Meanwhile, the randomised trial evidence supports rt-CGM use for improving neonatal health outcomes [2].

\section{Clinical CGM targets in pregnant individuals with type 1 diabetes}

The patterns of glycaemia during pregnancy have been studied for over five decades using laboratory and capillary glucose measures. These informed simple fasting, pre-meal and post-meal glucose targets in pregnant women with and without diabetes [31]. The patterns of glycaemia using CGM are more complex and require evidence-based CGM metrics based on pregnancy outcomes. As noted by Kristensen et al, day-to-day glucose control was suboptimal despite use of iCGM or rt-CGM. We still have much to learn on how best to adjust the timing and dosing of insulin, physical activity and dietary intake in relation to CGM data. The incorporation of clinical CGM based-targets may help users and clinicians to interpret CGM data and to agree specific, measurable and potentially attainable CGM targets over a typical 2-4 week antenatal clinic time-frame. Goal setting based on CGM-based targets could help overcome the current lack of glycaemic improvement in the second and third trimesters. 
CGM measures give insights into direct fetal exposure to maternal glycaemia and, unlike $\mathrm{HbA}_{1 \mathrm{c}}$, are not subject to changes in gestational physiology. To optimise day-to-day glucose control, women and clinicians should focus their attention on the dynamic CGM measures of fetal glucose exposure. The ATTD consensus CGM target recommendations suggest aiming for a TIR for 3.5-7.8 mmol/l of $>70 \%$ (16 h, $48 \mathrm{~min}$ ), TAR for $>7.8 \mathrm{mmol} / 1 \mathrm{lof}<25 \%(6 \mathrm{~h})$ and TBR for $<3.5 \mathrm{mmol} / \mathrm{l}$ of $<4 \%$ ( $1 \mathrm{~h}$ ) and TBR for $<3.0 \mathrm{mmol} / 1 \mathrm{lof}<1 \%$ (15 min) [3].

This ambitious target of $>70 \%$ TIR is currently only reached in the final 3-4 weeks of type 1 diabetes pregnancy, which is too late for optimal neonatal outcomes. In CONCEPTT, only $10 \%$ of women achieved a TIR of $>70 \%$ during the first and second trimesters, rising to $30 \%$ at 34 weeks. Almost twice as many achieved target $\mathrm{HbA}_{1 \mathrm{c}}$ levels. For optimal obstetric and neonatal outcomes, women and clinicians should aim to reach a TIR of $>70 \%$ ( $16 \mathrm{~h}, 48 \mathrm{~min}$ ) and a TAR of $<25 \%$ ( $6 \mathrm{~h}$ ), from as early as possible during pregnancy. Women who cannot achieve the TIR target of $>70 \%$ in the second and early third trimester should be encouraged that a 5\% increase in TIR is associated with clinically relevant improvements in neonatal health.

Duality of interest HRM reports having received speaker honoraria from Novo Nordisk, Roche, Medtronic and Abbott Diabetes Care. HRM sits on the Medtronic European Scientific Advisory Board and has received research support from Dexcom, Medtronic, Abbott Diabetes Care and Johnson \& Johnson outside the submitted work.

Contribution statement HRM is the sole contributor to this paper.

Open Access This article is distributed under the terms of the Creative Commons Attribution 4.0 International License (http:// creativecommons.org/licenses/by/4.0/), which permits unrestricted use, distribution, and reproduction in any medium, provided you give appropriate credit to the original author(s) and the source, provide a link to the Creative Commons license, and indicate if changes were made.

\section{References}

1. Kristensen K, Ögge LE, Sengpiel Vet al (2019) Continuous glucose monitoring in pregnant women with type 1 diabetes: an observational cohort study of 186 pregnancies. Diabetologia. https://doi. org/10.1007/s00125-019-4850-0

2. Feig DS, Donovan LE, Corcoy R et al (2017) Continuous glucose monitoring in pregnant women with type 1 diabetes (CONCEPTT): a multicentre international randomised controlled trial. Lancet. 390(10110):2347-2359. https://doi.org/10.1016/S0140-6736(17) 32400-5

3. Battelino T, Danne T, Amiel SA et al (2019) Clinical targets for continuous glucose monitoring data interpretation: recommendations from the international consensus on time-in-range. Diabetes Care (In press)

4. Kilpatrick ES (2004) HbA1c measurement. J Clin Pathol 57(4): 344-345. https://doi.org/10.1136/jcp.2003.010918

5. Radder JK, van Roosmalen $\mathrm{J}(2005) \mathrm{HbA}_{1 \mathrm{c}}$ in healthy, pregnant women. Neth J Med 63(7):256-259
6. Herranz L, Pallardo LF, Hillman N, Martin-Vaquero P, Villarroel A, Fernandez A (2007) Maternal third trimester hyperglycaemic excursions predict large-for-gestational-age infants in type 1 diabetic pregnancy. Diabetes Res Clin Pract 75(1):42-46. https://doi.org/10. 1016/j.diabres.2006.05.019

7. Murphy HR (2018) Intensive glycemic treatment during type 1 diabetes pregnancy: a story of (mostly) sweet success! Diabetes Care 41(8):1563-1571. https://doi.org/10.2337/dci18-0001

8. Law GR, Gilthorpe MS, Secher AL et al (2017) Translating $\mathrm{HbA}_{1 \mathrm{c}}$ measurements into estimated average glucose values in pregnant women with diabetes. Diabetologia. 60(4):618-624. https://doi. org/10.1007/s00125-017-4205-7

9. Bergenstal RM, Beck RW, Close KL et al (2018) Glucose management indicator (GMI): a new term for estimating A1C from continuous glucose monitoring. Diabetes Care 41(11):2275-2280. https:// doi.org/10.2337/dc18-1581

10. Murphy HR, Rayman G, Lewis K et al (2008) Effectiveness of continuous glucose monitoring in pregnant women with diabetes: randomised clinical trial. BMJ. 337:a1680. https://doi.org/10.1136/ bmj.a1680

11. Secher AL, Ringholm L, Andersen HU, Damm P, Mathiesen ER (2013) The effect of real-time continuous glucose monitoring in pregnant women with diabetes: a randomized controlled trial. Diabetes Care 36(7):1877-1883. https://doi.org/10.2337/dc122360

12. Law GR, Ellison GT, Secher AL et al (2015) Analysis of continuous glucose monitoring in pregnant women with diabetes: distinct temporal patterns of glucose associated with large-for-gestationalage infants. Diabetes Care 38(7):1319-1325. https://doi.org/10. 2337/dc15-0070

13. Bell R, Glinianaia SV, Tennant PW, Bilous RW, Rankin J (2012) Peri-conception hyperglycaemia and nephropathy are associated with risk of congenital anomaly in women with pre-existing diabetes: a population-based cohort study. Diabetologia. 55(4):936-947. https://doi.org/10.1007/s00125-012-2455-y

14. Persson M, Norman M, Hanson U (2009) Obstetric and perinatal outcomes in type 1 diabetic pregnancies: a large, population-based study. Diabetes Care 32(11):2005-2009. https://doi.org/10.2337/ dc09-0656

15. Mackin ST, Nelson SM, Kerssens JJ et al (2018) Diabetes and pregnancy: national trends over a 15 year period. Diabetologia. 61(5):1081-1088

16. Murphy HR, Bell R, Cartwright C et al (2017) Improved pregnancy outcomes in women with type 1 and type 2 diabetes but substantial clinic-to-clinic variations: a prospective nationwide study. Diabetologia. 60(9):1668-1677. https://doi.org/10.1007/s00125017-4314-3

17. Beck RW, Bergenstal RM, Riddlesworth TD, Kollman C (2019) The association of biochemical hypoglycemia with the subsequent risk of a severe hypoglycemic event: analysis of the DCCT data set. Diabetes Technol Ther 21(1):1-5. https://doi.org/10.1089/dia.2018. 0362

18. Mazze R, Yogev Y, Langer O (2012) Measuring glucose exposure and variability using continuous glucose monitoring in normal and abnormal glucose metabolism in pregnancy. J Matern Fetal Neonatal Med 25(7):1171-1175. https://doi.org/10.3109/ 14767058.2012 .670413

19. Ringholm L, Pedersen-Bjergaard U, Thorsteinsson B, Damm P, Mathiesen ER (2012) Hypoglycaemia during pregnancy in women with Type 1 diabetes. Diabet Med 29(5):558-566. https://doi.org/ 10.1111/j.1464-5491.2012.03604.x

20. Feig DS, Corcoy R, Donovan LE et al (2018) Pumps or multiple daily injections in pregnancy involving type 1 diabetes: a prespecified analysis of the CONCEPTT randomized trial. Diabetes Care 41(12):2471-2479. https://doi.org/10.2337/dc181437 
21. Murphy HR, Elleri D, Allen JM et al (2012) Pathophysiology of postprandial hyperglycaemia in women with type 1 diabetes during pregnancy. Diabetologia. 55(2):282-293. https://doi.org/10.1007/ s00125-011-2363-6

22. Mathiesen ER, Kinsley B, Amiel SA et al (2007) Maternal glycemic control and hypoglycemia in type 1 diabetic pregnancy: a randomized trial of insulin aspart versus human insulin in 322 pregnant women. Diabetes Care 30(4):771-776. https://doi.org/10.2337/ dc06-1887

23. Mathiesen ER, Hod M, Ivanisevic M et al (2012) Maternal efficacy and safety outcomes in a randomized, controlled trial comparing insulin detemir with NPH insulin in 310 pregnant women with type 1 diabetes. Diabetes Care 35(10):2012-2017. https://doi.org/10. 2337/dc11-2264

24. Secher AL, Stage E, Ringholm L, Barfred C, Damm P, Mathiesen ER (2014) Real-time continuous glucose monitoring as a tool to prevent severe hypoglycaemia in selected pregnant women with type 1 diabetes - an observational study. Diabet Med 31(3):352356. https://doi.org/10.1111/dme.12383

25. Stewart ZA, Wilinska ME, Hartnell S et al (2018) Day-and-night closed-loop insulin delivery in a broad population of pregnant women with type 1 diabetes: a randomized controlled crossover trial. Diabetes Care 41(7):1391-1399. https://doi.org/10.2337/ dc17-2534

26. Goudie RJ, Lunn D, Hovorka R, Murphy HR (2014) Pharmacokinetics of insulin aspart in pregnant women with type 1 diabetes: every day is different. Diabetes Care 37(6):e121-e122. https://doi.org/10.2337/dc13-2535
27. Neoh SL, Grisoni JA, Feig DS, Murphy HR, Group CC (2019) Dietary intakes of women with type 1 diabetes before and during pregnancy: a pre-specified secondary subgroup analysis among CONCEPTT participants. Diabet Med. https://doi.org/10.1111/ dme. 13937

28. Ritholz MD, Atakov-Castillo A, Beste M et al (2010) Psychosocial factors associated with use of continuous glucose monitoring. Diabet Med 27(9):1060-1065. https://doi.org/10.1111/j.14645491.2010.03061.x

29. Scott EM, Bilous RW, Kautzky-Willer A (2018) Accuracy, user acceptability, and safety evaluation for the FreeStyle Libre Flash Glucose Monitoring System when used by pregnant women with diabetes. Diabetes Technol Ther 20(3):180-188. https://doi.org/10. 1089/dia.2017.0386

30. Murphy HR, Elleri D, Allen JM et al (2011) Closed-loop insulin delivery during pregnancy complicated by type 1 diabetes. Diabetes Care 34(2):406-411. https://doi.org/10.2337/dc10-1796

31. Hernandez TL, Friedman JE, Van Pelt RE, Barbour LA (2011) Patterns of glycemia in normal pregnancy: should the current therapeutic targets be challenged? Diabetes Care 34(7):1660-1668. https://doi.org/10.2337/dc11-0241

Publisher's note Springer Nature remains neutral with regard to jurisdictional claims in published maps and institutional affiliations. 